УДК $630^{*} 6$

\title{
АЛГОРИТМ МАССОВОЙ КАДАСТРОВОЙ ОЦЕНКИ ЛЕСНЫХ ЗЕМЕЛЬ ПО ТАКСАЦИОННЫМ ПОКАЗАТЕЛЯМ НАСАЖДЕНИЙ
}

\author{
Романчиков Алексей Юрьевич1, \\ romanchicov@inbox.ru
}

\section{Ковязин Василий Федорович 1 ,} vfkedr@mail.ru

\author{
Животягина Нина Ивановна², \\ pozhni@mail.ru
}

\section{Киценко Анастасия Анатольевна 1 kna1994@bk.ru}

Данг Тхи Лан Ань 1 , lananhvtu2@gmail.com

1 Санкт-Петербургский горный университет, Россия, 199106, г. Санкт-Петербург, 21 линия ВО, 2.

2 Всероссийский научно-исследовательский институт лесной генетики, селекции и биотехнологии, Россия 394087, г. Воронеж, ул. Ломоносова, 105.

\begin{abstract}
Актуальность исследования обусловлена необходимостью разработки единого методического подхода к государственной кадастровой оценке земель лесного фонда. Это необходимо для рационального управления природными ресурсами, установления справедливой платы за пользование лесными землями и обеспечения концепции устойчивого развития лесного комплекса.

Цель: разработать алгоритм массовой кадастровой оценки лесных земель по минимально возможным учетным единицам таксационным выделам, что позволяет дифффернцировать их по качеству. Должна обеспечиваться возможность ее использования по всей России путем учета региональных особенностей заготовки лесных ресурсов.

Методы: дисконтирование денежных потоков от заготовки лесных ресурсов; регрессионный анализ связи между значениями таксационных показателей и продуктивностью лесных ресурсов; геоинформационное моделирование средствами МарInfo; проверка гипотезы о нормальности распределения полученных результатов; обеспечение работы алгоритма кадастровой оценки средствами MS Excel.

Результаты и выводы. Разработан алгоритм определения кадастровой стоимости лесных земель по таксационным выделам средствами MS Excel. Он позволяет определять кадастровую стоимость как повыдельно, так и в рамках районных и участковых лесничеств, используя таксационные показатели насаждений в качестве исходных данных. Алгоритм может изменяться путем модульного дополнения дисконитрованными денежнами потоками от заготовки природных ресурсов, характерных для конкретной лесорастительной зоны. Разработанный алгоритм испытан с использованием таксационных показателей для одного из участковых лесничеств на территории Ленинградской области, учитывая местные особенности заготовки природных ресурсов. Полученнье величины удельных показателей кадастровой стоимости распределены по нормальному закону, территориально высокие значения удельных показателей кадастровой стоимости приурочены к выделам с лучшими качественными и количественными таксационными показателями.
\end{abstract}

Ключевые слова:

Государственная кадастровая оценка, лесные земли, земли лесного фонда, лесные ресурсы, недревесная продукция леса.

\section{Актуальность и цель исследования}

Кадастровая оценка позволяет получить количественное представление о качестве земель лесного фонда. Такая информация позволяет принимать взвешенные и сбалансированные решения в сфере управления землями лесного фонда, обеспечивая экологический баланс территорий. В разрезе геотехнологий это важно, в первую очередь, при проектировании предприятий добывающей и обрабатывающей промышленности и маршрутов прохождения трасс линейных сооружений для обеспечения их деятельности. На территории России множество предприятий расположено в таежной зоне, поэтому их строительство напрямую сопряжено с изъятием земель лесного фонда. При раз- работке проектных решений и выборе наиболее предпочтительного варианта территориального размещения предприятий и объектов инфраструктуры необходимо обеспечить изъятие наиболее малоценных участков лесных земель, чтобы нанести минимальный ущерб экологическому благополучию территорий. Кадастровая стоимость в данном случае - наиболее универсальный показатель, который дает возможность принимать сбалансированные решения и обеспечивать устойчивое развитие осваиваемых территорий [1]. На 1 января 2018 г. [2] земли лесного фонда занимают 66 \% в общей структуре земельного фонда Российской Федерации, причем покрытые лесами земли, входящие в эту категорию, занимают 44 \% в распределении всех земель государства. 
Согласно новому закону «О государственной кадастровой оценке» [3] и утвержденных в дополнение к нему «Методических указаний о государственной кадастровой оценке» [4] государственная кадастровая оценка должна проводиться не по категориям земель как раньше, а по сегментам, характеризующим их использование.

Для покрытых древесной растительностью лесных земель, являющихся частью лесного фонда, которые чаще всего используются для заготовки продукции леса, можно применить сегмент, обозначенный законодателем как «Использование лесов».

Он делится на 4 группы: «Заготовка древесины», «Заготовка лесных ресурсов», «Лесные плантации» и «Резервные леса».

Описание групп приведено недостаточно точно, поэтому жесткое отнесение лесного участка к определенной группе невозможна.

Помимо этого, такое описание групп исключает возможность одновременной заготовки древесины и прочих лесных ресурсов. Стоит отметить, что новая методика предлагает оценивать леса только исходя из их использования для заготовки древесины без учета побочной продукции, а тем более экологической и рекреационной роли леса.

Это является значительным шагом назад, учитывая, что в методике Росземкадастра 2002 г. [5] видов использования предусматривалось намного больше.

В ходе предыдущих исследований $[6,7]$ нами предложена методика кадастровой оценки лесных земель, покрытых древесной растительностью, для целей их многоцелевого использования. Рассчитывать кадастровую стоимость предлагается как сумму дисконтированных денежных потоков: от заготовки древесины в спелых и перестойных насаждениях; пищевой, недревесной и лекарственной продукции леса на период в два оборота рубки спелых и перестойных насаждений. В качестве исходных данных нами рекомендуется использовать таксационные показатели насаждений и рыночную стоимость лесных и побочных ресурсов.

Важной особенностью нашей методики является тот факт, что оценка проводится для минимальных единиц деления лесного фонда - таксационных выделов, сведения о которых можно получить в таксационных описаниях лесничеств или путем инвентаризации насаждений рассматриваемого лесного участка [7].

Установлено, что значения удельных показателей кадастровой стоимости (УПКС) территориально распределены таким же образом, что и таксационные показатели, применявшиеся при расчетах. Значения УПКС по частоте появления распределены по нормальному закону, что соответствует экспериментальным данным о нормальном распределении таксационных показателей насаждений, если в них не проводились интенсивные рубки ухода [8].

В ходе разработки методики определения кадастровой стоимости лесных земель по выделам с использованием данных о стоимости лесных ресурсов, материалов таксационных описаний перед нами возник вопрос об оптимизации вычислений, поскольку в одном квартале может находиться 40-60 выделов, а на территории лесничества - более 2 тысяч таких лесных участков [9].
Таким образом, при таком количестве данных необходимо выработать алгоритм, который в дальнейшем может быть реализован с помощью программных средств. В нашем случае это будет табличный процесcop MS Excel, как один из наиболее распространенных, удобный для редактирования пользователем и обеспечивающий наглядность представления результата и взаимосвязи параметров между собой.

\section{Методы}

Представление результатов вычислений в табличной форме позволяет поэтапно и в реальном времени отражать процесс определения удельного показателя кадастровой стоимости, в особенности с учетом того, что исходные материалы таксационных описаний насаждений также являются таблицами.

Расчет УПКС представляется в виде набор отдельных алгоритмов для каждого из дисконтированных денежных потоков (ДДП), использованных при суммировании. Они подробно представлены в предыдущей публикации [7] и иллюстрируют связи между исходными таксационными показателями, промежуточными величинами, которые от них зависят, и служат основой для расчета ДДП, а также отражают итоговые значения, полученные в результате вычислений.

Для расчетов необходимо нормализовать все исходные данные, так как их представление в таксационных описаниях в некоторых случаях сложно поддается программной обработке. Исходные данные, которые применялись при расчетах УПКС, приведены в табл. 1.

Для расчета ДДП от заготовки грибов определяем денежные потоки от ежегодного сбора грибов в период времени от текущего момента до главной рубки, которая будет следовать за ближайшей, с учетом того, что 10 лет после главной рубки урожай грибов минимален [10]. Такой временной промежуток позволяет полностью оценивать весь потенциал участка лесных земель в плане обеспечения урожая грибов. В то же время дисконтирование, приводящее будущие доходы к настоящему времени, для такого продолжительного периода делает будущие значения к концу промежутка практически равными нулю, что дает возможность сравнивать его с «неограниченным количеством оборотов рубки» из модели Фаустманна $[11,12]$. Урожайность зависит от типа леса и считается средней за многолетний промежуток времени на крупную единицу площади, что сглаживает сезонные колебания объема сбора продукции. Здесь и далее при расчетах также применяется допущение о том, что рубка спелых и перестойных насаждений на участке будет сплошной и приуроченной к возрасту спелости главной породы [13].

Расчет ДДП от заготовки ягод ведется аналогично с допущением, что сбор ягод не прерывается после проведения главной рубки. Расчет ДДП от заготовки березового сока аналогичен, объем собираемого ресурса принимается из расчета в 10000 литров с 1 гектара для полностью березового древостоя с соответствующими поправками на его долю в составе, заготовка ведется в последние 3 года перед рубкой спелых и перестойных насаждений [10]. 
Таблица 1. Исходные данные, используемые при расчете УПКС

Table 1. Data used for cadastral value (per unit) calculation

\begin{tabular}{|c|c|c|c|}
\hline Название/Name & $\begin{array}{c}\text { Единицы } \\
\text { измерения } \\
\text { Measure unit }\end{array}$ & $\begin{array}{c}\text { Диапазон значений, использованных } \\
\text { при расчетах } \\
\text { Value range used in calculation }\end{array}$ & $\begin{array}{l}\text { Источник данных } \\
\text { Data source }\end{array}$ \\
\hline $\begin{array}{l}\text { Коэффициент состава древостоя } \\
\text { Species composition coefficient }\end{array}$ & $\begin{array}{c}\text { Единицы } \\
\text { Unit fraction }\end{array}$ & $0-10$ & $\begin{array}{l}\text { Таксационные описания насаждений } \\
\text { Forest inventory data }\end{array}$ \\
\hline $\begin{array}{l}\text { Тип лесорастительных условий } \\
\text { Forest type }\end{array}$ & - & $\begin{array}{l}\text { Деление на типы по Сукачеву } \\
\text { Forest type by Sukachev }\end{array}$ & $\begin{array}{l}\text { Материалы таксационных описаний } \\
\text { Forest inventory materials }\end{array}$ \\
\hline $\begin{array}{l}\text { Запас древесины } \\
\text { Standing volume }\end{array}$ & $\begin{array}{c}\mathrm{m}^{3} / \Gamma \mathrm{a} \\
\mathrm{m}^{3} \text { per ha }\end{array}$ & $0-400$ & $\begin{array}{l}\text { Материалы таксационных описаний } \\
\text { Forest inventory materials }\end{array}$ \\
\hline $\begin{array}{l}\text { Возраст древесной породы } \\
\text { Species age }\end{array}$ & Лет/years & $0-250$ & $\begin{array}{l}\text { Материалы таксационных описаний } \\
\text { Forest inventory materials }\end{array}$ \\
\hline $\begin{array}{l}\text { Возраст спелости породы } \\
\text { Species maturity age }\end{array}$ & Лет/years & $\begin{array}{c}60 \text { для мелколиственных } \\
60 \text { for small-leaved } \\
80 \text { для хвойных и твердолиственных } \\
80 \text { for pine and broad-leaved }\end{array}$ & $\begin{array}{l}\text { Правила заготовки древесины, Лесной } \\
\text { план субъекта Российской Федерации } \\
\text { Harvest and forestry policies for regions } \\
\text { of Russia }\end{array}$ \\
\hline $\begin{array}{l}\text { Средний диаметр (по породам) } \\
\text { Average diameter (by species) }\end{array}$ & $\mathrm{cm} / \mathrm{cm}$ & $5-50$ & $\begin{array}{l}\text { Таксационные описания } \\
\text { Forest inventory data }\end{array}$ \\
\hline $\begin{array}{l}\text { Средняя высота (по породам) } \\
\text { Average height (by species) }\end{array}$ & $\mathrm{M} / \mathrm{m}$ & $5-35$ & $\begin{array}{l}\text { Таксационные описания } \\
\text { Forest inventory data }\end{array}$ \\
\hline $\begin{array}{l}\text { Коэффициент дисконтирования } \\
\text { Discount coefficient }\end{array}$ & $\%$ & $1-5$ & $\begin{array}{l}\text { Материалы научных исследований } \\
\text { Materials of scientific research }\end{array}$ \\
\hline $\begin{array}{l}\text { Цена единицы ресурса } \\
\text { Unit cost }\end{array}$ & $\begin{array}{l}\text { p./ед } \\
\text { rub/unit }\end{array}$ & $\begin{array}{c}\text { в зависимости от вида ресурса } \\
\text { depending of resource type }\end{array}$ & $\begin{array}{l}\text { Росстат, данные организаций } \\
\text { Russian statistical agency, producers data }\end{array}$ \\
\hline $\begin{array}{l}\text { Рентабельность продажи лесной } \\
\text { продукции } \\
\text { Profitability of sales }\end{array}$ & $\%$ & $\begin{array}{l}\text { в зависимости от вида ресурса } \\
\text { depending of resource type }\end{array}$ & $\begin{array}{l}\text { Росстат, данные организаций } \\
\text { Russian statistical agency, producers data }\end{array}$ \\
\hline
\end{tabular}

Расчет ДДП от заготовки древесины ведется отдельно для хвойных и лиственных пород деревьев вследствие значительного различия в стоимости продуктов их деревообработки. Учитываются основные лесообразующие породы для Ленинградской области - ель, сосна, береза, осина, ольха. Объем древесины определяется исходя из таксационных описаний с учетом прироста древесины на выделе к моменту главной рубки, определяемого по авторским формулам на основе материалов лесотаксационного справочника [14]. Рубка является сплошной и приурочена к возрасту спелости преобладающей породы, после чего считается, что на выделе будет выращен древостой такого же состава и свойств. Значения запаса и возраста для групп пород принимаются средневзвешенными в зависимости от доли конкретной породы в составе насаждения.

ДДП от заготовки хвои рассчитывается исходя из сбора $70 \%$ еловой и сосновой хвои после проведения рубки спелых и перестойных насаждений на выделе. Расчет объема запаса ресурса ведется на основе формул, представленных в работе [10].

Расчет ДДП от заготовки живицы ведется исходя из предположения, что сосновая живица заготавливается в течение 10 лет перед рубкой спелых и перестойных насаждений. Объем подсочки и число карр определяется на основаннии методики, представленной в работе [10].

Определение ДДП от заготовки коры и бересты осуществляется на основании расчетов [8], согласно которым $13 \%$ от общего запаса древесины в среднем приходится на кору. Заготовка также приурочена к рубке спелых и перестойных насаждений.

Вопрос о величине ставки дисконтирования остается открытым и требует значительного обоснова- ния - в различных исследованиях она варьируется от 1 до $5 \%$ [15-17]. Нами выбрано значение в $2 \%$ как наиболее часто встречающееся.

Цены на продукцию колеблются со временем и должны ежегодно быть актуализованы. Нами применялись данные из открытых источников и материалов Росстата. Расходная часть при расчете ДДП должна определяться как сумма расходов, возникающих при заготовке древеснины, лесхозяйственных мероприятиях, лесовосстановлении и охране леса. Однако здесь мы сталкиваемся с рядом трудностей - не вся указнная выше информация находится в открытом доступе и виде удельных показателей. Данные из лесных планов не могут полностью отражать картину, поскольку в силу ограниченности бюджетов некоторые мероприятия реализуются не в полном объеме, а определение удельных показателей для таксационных выделов также затруднено.

Из-за неопределенности при учете расходов в расчете ДДП нами было принято допущение о понижении величины доходов от заготовки того или иного ресурса в зависимости от рентабельности его продажи. Источник данных - Росстат или отчеты крупных заготовителей пищевой продукции леса.

Некоторые упомянутые выше величины определяются путем проведения вычислений и зависят от исходных данных. В табл. 2 представлен диапазон значений, которые они принимают, и данные, которые применяются для расчетов.

Диапазон значений, которые принимают определенные нами ДДП, а также взаимосвязь результатов с используемыми промежуточными величинами представлены ниже (табл. 3). 
Таблица 2. Промежуточные величины, используемые при расчетах

Table 2. Intermediate values used during calculation

\begin{tabular}{|c|c|c|c|}
\hline Название/Name & $\begin{array}{c}\text { Единицы } \\
\text { измерения } \\
\text { Measure units } \\
\end{array}$ & $\begin{array}{l}\text { Диапазон } \\
\text { значений } \\
\text { Value range }\end{array}$ & $\begin{array}{l}\text { Необходимые данные для расчета } \\
\text { Necessary data }\end{array}$ \\
\hline $\begin{array}{l}\text { Преобладающая порода } \\
\text { Dominating tree species }\end{array}$ & - & - & $\begin{array}{l}\text { Коэффициент состава древостоя } \\
\text { Species composition coefficient }\end{array}$ \\
\hline $\begin{array}{l}\text { Запас древесины с поправкой на прирост } \\
\text { Standing volume corrected by annual increment }\end{array}$ & $\begin{array}{c}\mathrm{m}^{3} / \Gamma \mathrm{a} \\
\mathrm{m}^{3} \text { per ha }\end{array}$ & $0-600$ & $\begin{array}{l}\text { Запас древесины; } \\
\text { Коэффициент состава древостоя; } \\
\text { Возраст породы (по породам) } \\
\text { Standing volume } \\
\text { Species composition coefficient } \\
\text { Age (by species) }\end{array}$ \\
\hline $\begin{array}{l}\text { Запас грибов (по видам) } \\
\text { Mushroom stock (by species) }\end{array}$ & $\begin{array}{l}\kappa г / г \mathrm{a} \\
\mathrm{kg} / \mathrm{ha}\end{array}$ & $0-5,1$ & $\begin{array}{l}\text { Тип лесорастительных условий; } \\
\text { Преобладающая порода } \\
\text { Forest type } \\
\text { Dominating tree species }\end{array}$ \\
\hline $\begin{array}{l}\text { Прибыль от сбора грибов (по каждому виду) } \\
\text { Mushroom harvest profit }\end{array}$ & $\begin{array}{l}\mathrm{p} . / \mathrm{K} \Gamma \\
\mathrm{rub} / \mathrm{kg}\end{array}$ & $25-130$ & $\begin{array}{l}\text { Цена единицы ресурса (грибы); } \\
\text { Рентабельность продажи продукции (грибы) } \\
\text { Unit cost (mushrooms) } \\
\text { Profitability of sales (mushrooms) }\end{array}$ \\
\hline $\begin{array}{l}\text { Ежегодная удельная прибыль от заготовки } \\
\text { грибов } \\
\text { Annual profit from mushroom harvest per ha }\end{array}$ & $\begin{array}{l}\text { р./гa } \\
\text { rub per ha }\end{array}$ & $0-685$ & $\begin{array}{l}\text { Запас грибов (по видам); } \\
\text { Прибыль от сбора грибов (по каждому виду) } \\
\text { Mushroom stock (by species) } \\
\text { Mushroom harvest profit }\end{array}$ \\
\hline $\begin{array}{l}\text { Время до главной рубки (преобладающая } \\
\text { порода) } \\
\text { Time to harvesting (for dominating tree species) }\end{array}$ & лет/years & $0-80$ & $\begin{array}{l}\text { Коэффициент состава древостоя; } \\
\text { Возраст породы (по породам); } \\
\text { Преобладающая порода; } \\
\text { Возраст спелости (по породам) } \\
\text { Species composition coefficient } \\
\text { Age (by species) } \\
\text { Dominating tree species } \\
\text { Maturity age (by species) } \\
\end{array}$ \\
\hline $\begin{array}{l}\text { Ежегодная прибыль от заготовки грибов с } \\
\text { учетом рубки главного пользования } \\
\text { Annual profit from mushroom harvest considering } \\
\text { final felling }\end{array}$ & $\begin{array}{l}\mathrm{p} . / \text { га } \\
\mathrm{rub} / \mathrm{ha}\end{array}$ & $0-203$ & $\begin{array}{l}\text { Преобладающая порода; } \\
\text { Коэффициент состава древостоя; } \\
\text { Время до главной рубки; } \\
\text { Ежегодная удельная прибыль от заготовки грибов; } \\
\text { Коэффициент дисконтирования } \\
\text { Dominating tree species } \\
\text { Species composition coefficient } \\
\text { Time to harvesting (for dominating tree species) } \\
\text { Annual profit from mushroom harvest per ha } \\
\text { Discount coefficient }\end{array}$ \\
\hline $\begin{array}{l}\text { Возраст рубки преобладающей породы } \\
\text { Age of dominating tree species felling }\end{array}$ & лет/years & 60,80 & $\begin{array}{l}\text { Преобладающая порода } \\
\text { Dominating tree species }\end{array}$ \\
\hline $\begin{array}{l}\text { Удельный запас вида ягод на выделе } \\
\text { Berry stock (by species) }\end{array}$ & $\begin{array}{l}\kappa г / г \mathrm{a} \\
\mathrm{kg} / \mathrm{ha}\end{array}$ & $0-40$ & $\begin{array}{l}\text { Тип лесорастительных условий; } \\
\text { Преобладающая порода } \\
\text { Forest type } \\
\text { Dominating tree species }\end{array}$ \\
\hline $\begin{array}{l}\text { Прибыль от заготовки ягод (по видам) } \\
\text { Profit from berry species harvest }\end{array}$ & $\begin{array}{c}\mathrm{p} . / \mathrm{k} \Gamma \\
\mathrm{rub} / \mathrm{kg}\end{array}$ & $11-36$ & $\begin{array}{l}\text { Цена единицы ресурса (ягоды); } \\
\text { Рентабельность продажи продукции (ягоды) } \\
\text { Unit cost (berries) } \\
\text { Profitability of sales (berries) }\end{array}$ \\
\hline $\begin{array}{l}\text { Ежегодная удельная прибыль от заготовки ягод } \\
\text { Annual berry harvest profit per ha }\end{array}$ & $\begin{array}{l}\text { p./гa } \\
\text { rub per ha }\end{array}$ & $0-915$ & $\begin{array}{l}\text { Удельный запас вида ягод на выделе; } \\
\text { Прибыль от заготовки ягод (по видам) } \\
\text { Berry stock (by species) } \\
\text { Profit from berry species harvest }\end{array}$ \\
\hline $\begin{array}{l}\text { Запас хвои (сосна) } \\
\text { Needle stock (pine) }\end{array}$ & $\begin{array}{c}\kappa г / г \mathrm{a} \\
\mathrm{kg} \text { per ha }\end{array}$ & $0-13965$ & $\begin{array}{l}\text { Запас древесины (сосна) с поправкой на прирост; } \\
\text { Средний диаметр сосны на выделе } \\
\text { Standing volume corrected by annual increment for } \\
\text { pine species } \\
\text { Average pine diameter for forest site }\end{array}$ \\
\hline $\begin{array}{l}\text { Запас хвои (ель) } \\
\text { Needle stock (fir) }\end{array}$ & $\begin{array}{c}\kappa г / г \mathrm{a} \\
\mathrm{kg} \text { per ha }\end{array}$ & 0-18706 & $\begin{array}{l}\text { Запас древесины (ель) с поправкой на прирост; } \\
\text { Средний диаметр (ель) } \\
\text { Standing volume corrected by annual increment (fir) } \\
\text { Average diameter (fir) }\end{array}$ \\
\hline $\begin{array}{l}\text { Годовой объем заготовки березового сока } \\
\text { Annual volume of birch sap harvest }\end{array}$ & $\begin{array}{ll}\pi / \Gamma a \\
\text { l/ha } \\
\end{array}$ & $0-9000$ & $\begin{array}{l}\text { Коэффициент состава древостоя (береза) } \\
\text { Species composition coefficient (birch) }\end{array}$ \\
\hline Число карр/Number of blazes & ед/units & $0-19$ & Средний диаметр (сосна)/Average diameter (pine) \\
\hline $\begin{array}{l}\text { Сумма площадей сечений абсолютно полного } \\
\text { древостоя } \\
\text { Basal area of full stand }\end{array}$ & $\mathrm{M}^{2} / \mathrm{m}^{2}$ & $3,54-35,45$ & $\begin{array}{l}\text { Средняя высота (сосна); } \\
\text { Коэффициент состава древостоя (сосна) } \\
\text { Pine average height } \\
\text { Species composition coefficient (pine) }\end{array}$ \\
\hline $\begin{array}{l}\text { Запас коры, запас бересты } \\
\text { Bark stock and birch bark stock }\end{array}$ & $\begin{array}{c}\kappa г / г \mathrm{a} \\
\mathrm{kg} \text { per ha }\end{array}$ & $9,82-96,31$ & $\begin{array}{l}\text { Запас древесины с поправкой на прирост (все породы) } \\
\text { Standing volume corrected by annual increment (all species) }\end{array}$ \\
\hline
\end{tabular}


Таблица 3. Полученные значения ДДП от заготовки различных видов продукции леса и необходимые величины для их расчета

Table 3. DCF values got from different forest resources harvesting and necessary values for calculation

\begin{tabular}{|c|c|c|c|}
\hline Название/Name & $\begin{array}{c}\text { Единица } \\
\text { измерения } \\
\text { Measure unit }\end{array}$ & $\begin{array}{c}\text { Необходимые данные для расчета } \\
\text { Necessary data }\end{array}$ & $\begin{array}{l}\text { Диапазон значений, } \\
\text { полученных в ре- } \\
\text { зультате расчетов } \\
\text { Results range }\end{array}$ \\
\hline $\begin{array}{l}\text { ДДП - заготовка } \\
\text { древесины (по поро- } \\
\text { дам) } \\
\text { DCF - timber harvest } \\
\text { (by species) }\end{array}$ & $\begin{array}{c}\mathrm{p} . / \mathrm{ra} \\
\mathrm{rub} / \mathrm{ha}\end{array}$ & $\begin{array}{l}\text { Возраст главной рубки преобладающей породы; время до главной } \\
\text { рубки; цена единицы ресурса (древесина); запас древесины с уче- } \\
\text { том текущего прироста (по породам); коэффициент дисконтирова- } \\
\text { ния; рентабельность продажи заготовленной древесины } \\
\text { Age of dominating tree species felling; Time to harvesting (for } \\
\text { dominating tree species); Unit cost (timber); Standing volume } \\
\text { considering annual increment (by species); Discount coefficient; } \\
\text { Profitability of sales (timber) }\end{array}$ & $0-35000$ \\
\hline $\begin{array}{l}\text { ДДП - заготовка } \\
\text { грибов } \\
\text { DCF - mushroom } \\
\text { harvest }\end{array}$ & $\begin{array}{l}\text { p./гa } \\
\text { rub per ha }\end{array}$ & $\begin{array}{l}\text { Ежегодная прибыль от заготовки грибов с учетом рубки главного } \\
\text { пользования; возраст рубки преобладающей породы; преобладаю- } \\
\text { щая порода; время до главной рубки } \\
\text { Annual profit from mushroom harvest considering final felling; Age of } \\
\text { dominating tree species felling; Dominating tree species; Time to main harvest }\end{array}$ & $0-16000$ \\
\hline $\begin{array}{l}\text { ДДП - заготовка } \\
\text { ягод } \\
\text { DCF - berry harvest }\end{array}$ & $\begin{array}{c}\mathrm{p} . / \mathrm{ra} \\
\mathrm{rub} / \mathrm{ha}\end{array}$ & $\begin{array}{l}\text { Возраст главной рубки преобладающей породы; время до главной } \\
\text { рубки; годовая прибыль от заготовки ягод на выделе; коэффициент } \\
\text { дисконтирования } \\
\text { Age of dominating tree species felling; Time to main harvest; Annual } \\
\text { profit from berry harvest; Discount coefficient }\end{array}$ & 0-19200 \\
\hline $\begin{array}{l}\text { ДДП - заготовка } \\
\text { хвои } \\
\text { DCF - needle harvest }\end{array}$ & $\begin{array}{l}\mathrm{p} . / \mathrm{ra} \\
\mathrm{rub} / \mathrm{ha}\end{array}$ & $\begin{array}{l}\text { Возраст главной рубки преобладающей породы; время до главной } \\
\text { рубки; запас сосновой и еловой хвои; цена единицы ресурса (хвоя); } \\
\text { коэффициент дисконтирования; рентабельность продажи продук- } \\
\text { ции (хвои от лесозаготовки) } \\
\text { Age of dominating tree species felling; Time to main harvest; Unit cost } \\
\text { (needle); Discount coefficient; Profitability of sales (needle) }\end{array}$ & $0-4500$ \\
\hline $\begin{array}{l}\text { ДДП - заготовка } \\
\text { березового сока } \\
\text { DCF - birch sap } \\
\text { harvest }\end{array}$ & $\begin{array}{l}\mathrm{p} . / \mathrm{ra} \\
\mathrm{rub} / \mathrm{ha}\end{array}$ & $\begin{array}{l}\text { Возраст главной рубки преобладающей породы; цена единицы } \\
\text { ресурса (березовый сок); годовой объем заготовки березового сока; } \\
\text { время до главной рубки; коэффициент дисконтирования; рента- } \\
\text { бельность продажи продукции (березовый сок) } \\
\text { Age of dominating tree species felling; Unit cost (birch sap); Annual } \\
\text { volume of birch sap harvest; Time to main harvest; Discount coefficient; } \\
\text { Profitability of sales (birch sap) }\end{array}$ & $0-32700$ \\
\hline $\begin{array}{l}\text { ДДП - заготовка } \\
\text { живицы } \\
\text { DCF - galipot harvest }\end{array}$ & $\begin{array}{c}\mathrm{p} . / \mathrm{ra} \\
\mathrm{rub} / \mathrm{ha}\end{array}$ & $\begin{array}{l}\text { Возраст главной рубки преобладающей породы; цена единицы } \\
\text { ресурса (живица); число карр подсочки; сумма площадей сечений } \\
\text { древостоя; время до главной рубки; коэффициент дисконтирова- } \\
\text { ния; рентабельность продажи продукции (живица) } \\
\text { Age of dominating tree species felling; Unit cost (galipot); Number of } \\
\text { blazes; Basal area of full stand; Time to main harvest; Discount } \\
\text { coefficient; Profitability of sales (galipot) }\end{array}$ & $0-1500$ \\
\hline $\begin{array}{l}\text { ДДП - заготовка } \\
\text { коры и бересты } \\
\text { DCF - bark harvest }\end{array}$ & $\begin{array}{c}\mathrm{p} . / \mathrm{ra} \\
\mathrm{rub} / \mathrm{ha}\end{array}$ & $\begin{array}{l}\text { Возраст главной рубки преобладающей породы; цена единицы } \\
\text { ресурса (кора и береста); запас коры и бересты; время до главной } \\
\text { рубки; коэффициент дисконтирования; рентабельность продажи } \\
\text { продукции (кора и береста) } \\
\text { Age of dominating tree species felling; Unit cost (bark); Bark stock; } \\
\text { Time to main harvest; Discount coefficient; Profitability of sales (bark) }\end{array}$ & $2100-6100$ \\
\hline
\end{tabular}

\section{Результаты}

Расчет урожайности проводился согласно работам отечественных исследователей, изучавших таежную зону Северо-Запада Российской Федерации [10]. Текущий прирост рассчитан на основании авторской адаптации материалов лесотаксационных справочников [14]. Вычисление ДДП проводилось по авторской методике [7], которая является модификацией модели Фаустманна и методики Росземкадастра 2002 г.

Вычисления проводились для каждого выдела отдельно. Использование табличного процессора обеспечило наглядное представление о промежуточных расчетах и динамическом изменении всех промежуточных величин. Это дает возможность оперативно выявлять ошибки в расчетных формулах, некорректные исходные данные, анализировать полученные результаты. Гибкость работы с процессором позволяет быстро корректировать алгоритм при изменениях структуры расчетов, добавлении новых источников дисконтированных денежных потоков, легко модифицировать способ представления информации.

В качестве апробации алгоритма использованы материалы таксационных описаний Линдуловского участкового лесничества Рощинского районного лесничества. Взяты данные по 150 выделам, и проведен расчет УПКС для каждого из них как сумма ДДП от потенциального использования различных лесных ресурсов. Результат выполнения вычислений приведен на рисунке. Приведены значения таксационных показателей, используемых как исходные данные, и полученные УПКС как результат суммирования ДДП от заготовки описанных выше ресурсов. В скрытой части таблицы (между столбцами Z и DB) рассчитываются все промежуточные величины и значения ДДП, вводятся единые для всех выделов величины (ставка дисконтирования, цены на единицу продукции и т. д.). 


\begin{tabular}{|c|c|c|c|c|c|c|c|c|c|c|c|c|c|c|c|c|c|c|c|c|c|c|c|c|c|c|c|}
\hline \multirow{2}{*}{$\frac{4}{1}$} & A & $B$ & c & D & $\mathrm{E}$ & $\mathrm{F}$ & G & $\mathrm{H}$ & I & J & K & L & M & $\mathrm{N}$ & $\begin{array}{ll}0 & P \\
\end{array}$ & $\mathrm{P}$ & Q & $R$ & s & 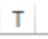 & U & $\mathrm{v}$ & W & $\mathrm{X}$ & $\mathrm{Y}$ & $z$ & $\mathrm{DB}$ \\
\hline & & & \multicolumn{5}{|c|}{ доля пород } & \multicolumn{5}{|c|}{ возраст пород } & \multicolumn{5}{|c|}{ высота } & \multicolumn{5}{|c|}{ диаметр } & & & \multirow[b]{2}{*}{$\begin{array}{l}\text { домин. } \\
\text { порода }\end{array}$} & \multirow[b]{2}{*}{$\begin{array}{l}\text { тип } \\
\text { леса }\end{array}$} & \multirow[b]{2}{*}{ УПКС } \\
\hline 2 & выдел & площады & & C E & Б & Ол & Oc & & $C$ E & & Ол & Oc & $\mathrm{E}$ & $C$ E & Б 0 . & Ол О & Dc & $\mathrm{E}$ & $C \mathrm{E}$ & Б & Ол С & Oc & $\begin{array}{l}\text { sanac, } \\
\text { м3/гаa }\end{array}$ & тлу & & & \\
\hline 3 & 1 & 0.2 & 6 & 1 & 3 & 0 & 0 & 65 & 65 & 50 & & & 20 & 191 & 18 & & & 24 & 24 & 18 & & & 232 & K & & EK & 60006.842 \\
\hline 4 & 2 & 0.1 & 7 & 0 & 3 & 0 & 0 & 60 & & 50 & & & 22 & & 19 & & & 24 & & 18 & & & 268 & K & E & EK & 67797.215 \\
\hline 5 & 3 & 0.8 & 7 & 1 & 1 & 0 & 0 & 70 & 65 & 55 & & & 23 & 202 & 20 & & & 26 & 242 & 20 & & & 286 & K & E & EK & 56301.13 \\
\hline 6 & 4 & 0.2 & 2 & 1 & 3 & 4 & 0 & 65 & 65 & 60 & 56 & & 21 & 191 & 191 & 18 & & 26 & 262 & 22 & 20 & & 123 & тто & ол & Олтто & 31194.799 \\
\hline 7 & 5 & 1.3 & 5 & 1 & 3 & 0 & 1 & 60 & 60 & 55 & & 60 & 19 & 191 & 19 & & 20 & 22 & 222 & 20 & & 24 & 151 & 4 & E & EY & 55945.45 \\
\hline 8 & 6 & 0.9 & & & & & & & & & & & & & & & & & & & & & & & & & \\
\hline 9 & 7 & 0.6 & 3 & 0 & 5 & 0 & 2 & 70 & & 50 & & 50 & 21 & & 18 & & 20 & 18 & & 26 & & 24 & 172 & 4 & 5 & 54 & 56799.395 \\
\hline 10 & 8 & 0.1 & 10 & 0 & 0 & 0 & 0 & 75 & & & & & 23 & & & & & 26 & & & & & 261 & K & E & EK & 50283.541 \\
\hline 11 & 9 & 3.3 & 2 & 0 & 6 & 0 & 2 & 50 & & 50 & & 50 & 19 & & 18 & & 20 & 20 & & 20 & & 24 & 172 & 4 & 5 & 54 & 67290.516 \\
\hline 12 & 10 & 0.9 & 0 & 1 & 6 & 2 & 1 & & 70 & 70 & 65 & 60 & & 202 & 201 & 19 & 20 & & 262 & 20 & 22 & 26 & 160 & тто & 5 & БтTо & 28660.589 \\
\hline 13 & 11 & 2 & 5 & 2 & 2 & 0 & 1 & 80 & 75 & 65 & & 60 & 23 & 201 & 19 & & 21 & 26 & 242 & 20 & & 26 & 268 & & E & E4 & 56341.25 \\
\hline 14 & 12 & 1.4 & 5 & 3 & 2 & 0 & 0 & 65 & 55 & 50 & & & 17 & 171 & 16 & & & 20 & 20 & 16 & & & 197 & & E & EY & 63239.653 \\
\hline 15 & 13 & 1.1 & 5 & 0 & 3 & 0 & 2 & 80 & & 65 & & 60 & 22 & & 19 & & 20 & 26 & & 20 & & 26 & 268 & 4 & E & EY & 52897.363 \\
\hline 16 & 14 & 1.7 & 2 & 1 & 4 & 0 & 3 & 65 & 65 & 55 & & 55 & 21 & 191 & 19 & & 21 & 26 & 242 & 20 & & 26 & 186 & 4 & 5 & 54 & 56285.738 \\
\hline 17 & 15 & 2.6 & 0 & 3 & 5 & 0 & 2 & & 65 & 55 & & 50 & & 212 & 22 & & 23 & & 242 & 22 & & 24 & 215 & & 5 & 54 & 64975.325 \\
\hline 18 & 16 & 0.6 & 4 & 0 & 6 & 0 & 0 & 65 & & 55 & & & 21 & & 19 & & & 26 & & 20 & & & 160 & & 5 & 54 & 62040.102 \\
\hline 19 & 17 & 2.9 & 2 & 3 & 5 & 0 & 0 & 60 & 60 & 55 & & & 20 & 191 & 19 & & & 24 & 24 & 18 & & & 224 & 4 & 5 & 54 & 74097.896 \\
\hline 20 & 18 & 0.3 & 0 & 1 & 9 & 0 & 0 & & 70 & 50 & & & & 171 & 17 & & & & 22 & 16 & & & 124 & тто & 5 & БТТО & 49569.415 \\
\hline 21 & 1 & 1.6 & 0 & 10 & 0 & 0 & 0 & & 50 & & & & & 14 & & & & & 16 & & & & 160 & & 'C & CБ & 64634.769 \\
\hline 22 & 2 & 1.5 & 4 & 6 & 0 & 0 & 0 & 60 & 60 & & & & 21 & 19 & & & & 22 & 22 & & & & 237 & & C & $C 4$ & 59736.022 \\
\hline 23 & 3 & 0.4 & 4 & 6 & 0 & 0 & 0 & 60 & 60 & & & & 19 & 19 & & & & 22 & 22 & & & & 224 & 4 & 'c & $\mathrm{Cl}$ & 57430.038 \\
\hline 24 & 4 & 0.7 & 5 & 0 & 1 & 3 & 1 & 80 & & 65 & 65 & 60 & 23 & & $\begin{array}{ll}20 & 1\end{array}$ & 18 & 21 & 26 & & 20 & 22 & 21 & 268 & K & E & EK & 43325.036 \\
\hline 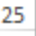 & 5 & .8 & 6 & 4 & 0 & 0 & 0 & 70 & 65 & & & & 20 & 20 & & & & 24 & 22 & & & & 214 & 4 & E & EY & 51679.724 \\
\hline 26 & 6 & 0.5 & 5 & 3 & 2 & 0 & 0 & 55 & 60 & 50 & & & 18 & 181 & & & & 20 & 22 & 16 & & & 214 & & E & EY & 60836.94 \\
\hline
\end{tabular}

Рисунок. Результаты работы алгоритма в MS Excеl (снимок с экрана)

Figure. Results of algorithm processing (MS Excel screenshot)

После проведения расчетов можно определить средние и медианные значения показателей по всем выделам, определить максимальные и минимальные значения. В дальнейшем это помогает проверить гипотезу о нормальности распределения полученных значений УПКС, что соответствует результатам наблюдений отечественных ученых [8] о нормальности распределения таксационных показателей в естественных древостоях. В ходе апробации полученные значения УПКС варьировались от 20000 до 80000 р./га, среднее значение составило 50800 р./га, медианное 53000 р./га.

\section{Выводы}

Выработка алгоритма кадастровой оценки - безусловно, важный и необходимый процесс, особенно применимый к участкам, предназначенным для лесопользования. В западных странах программное обеспечение подобного рода широко распространено Forestry DSS - системы для помощи при управлении лесным хозяйством, разработаны во многих университетах, а 5-7 наиболее популярных из них получают широкое применение [18, 19].

Они обеспечивают возможность пространственного анализа данных, расчета продолжительности оборотов рубки, определения чистого дисконтированного дохода от использования лесных ресурсов тем или иным способом.

Данное исследование представляет собой основу для разработки собственной системы принятия решений, учитывающей особенности управления российским лесным хозяйством, а именно отсутствием частной собственности на земли лесного фонда и общей неразвитостью рынка и системы организации заготовок некоторых видов лесных ресурсов.

Важным направлением развития является совершенствование самой методики. В предлагаемой методике основной акцент делется на эксплуатационное использование лесов. Экологическая и рекреационная роли леса имеют значительный экономический эффект, однако величина его является дискуссионным вопросом $[20,21]$. В дальнейшем они будут включены в алгоритм как одни из слагаемых в сумме дисконтированных денежных потоков от использования лесов.

Табличный процессор, помимо описанных выше преимуществ, имеет и ряд недостатков. Для работы в обязательном порядке требуется лицензионное программное обеспечение. Пользователь вынужден взаимодействовать с большим количеством данных на экране, перемещаясь при помощи полос прокрутки, что замедляет процесс. Величины, которые не входят в табличную структуру, но должны быть отображены, их необходимо приводить отдельно от таблицы или в ее теле, что нарушает представление данных. Эта проблема будет решена при написании специализированной программы на объектно-ориентированном языке программирования. Процедуры ввода и вывода данных будут разделены, промежуточные вычисления скрыты, а результаты их доступны при необходимости. Это перспективный путь развития, который мы планируем развивать в дальнейшем.

Также необходимо организовать сбор значительного объема статистической информации о влиянии конкретных лесничеств на экономику региона и интерпретировать полученные данные в денежном выражении. Задача является сложной в том плане, что 
необходимо грамотно учесть относительный вклад этих эффектов в суммарный удельный показатель кадастровой стоимости, чтобы он не принимал завышенных значений. Это связано с различными трактовками исследователей вклада лесов в поглощение углерода, поддержание экологического баланса и

\section{СПИСОК ЛИТЕРАТУРЫ}

1. Павлова В.А., Уварова Е.Л. Новейшие технологии в кадастровой деятельности // Записки Горного института. - 2017. T. 225. - C. 313-319. DOI: 10.18454/PMI.2017.3.313

2. Государственный (национальный) доклад о состоянии и использовании земель в Российской Федерации. URL: https:// rosreestr.ru/site/activity/sostoyanie-zemel-rossii/gosudarstvennyynatsionalnyy-doklad-o-sostoyanii-i-ispolzovanii-zemel-vrossiyskoy-federatsii/ (дата обращения: 08.01.2019).

3. О государственной кадастровой оценке: Федеральный закон от 03.07.2016 г. № 237-ФЗ (ред. 29.07.2017) // Справочноправовая система «Консультант Плюс». URL: http://www. consultant.ru/document/cons doc LAW 200504/ (дата обращения: 14.01.2019)

4. Об утверждении методических указаний о государственной кадастровой оценке: приказ Минэкономразвития от 12.05.2017 № 226 // Справочно-правовая система «Консультант Плюс». URL: http://www.consultant.ru/document/cons_doc_LAW 217405/ (дата обращения: 14.01.2019)

5. Об утверждении методики государственной кадастровой оценки земель лесного фонда Российской Федерации: приказ Росземкадастра от 17.10.2002 г. №П/336 // Справочно-правовая система «Консультант Плюс». URL: http://www. consultant.ru/ document/cons_doc_LAW_40052/ (дата обращения 14.01.2019).

6. Kovyazin V., Romanchikov A. Belyaev V. Use of forest inventory data as a new method for cadastral valuation of forestlands in North-West Russia // Forestry Studies - 2014. - V. 61. - P. 69-78.

7. Романчиков А.Ю. Кадастровая оценка покрытых древесной растительностью лесных земель таежной зоны Северо-Запада Российской Федерации при многоцелевом использовании их ресурсного потенциала: дис. ... канд. техн. наук. - СПб. 2017. $-231 \mathrm{c}$.

8. Основы лесного хозяйства и таксация леса / Сост. В.Ф. Ковязин, А.Н. Мартынов, Е.С. Мельников и др. - СПб.: Изд-во «Лань», 2012. - 432 c.

9. Минаев В.Н., Леонтьев Л.Л., Ковязин В.Ф. Таксация леса. СПб.: Лань, 2017. - 240 с.

10. Грязькин А.В., Кондратенко Н.Н., Пона Д.С. Недревесная продукция леса. - СПб.: Изд-во Политехнического университета, 2006. -338 c. здоровья населения. Значения могут варьироваться на порядок в зависимости от взглядов конкретного ученого, поэтому необходимо выработать сбалансированный взвешенный подход, так как полученные значения стоимости непосредственно будут влиять на экономическую и ситуацию в лесном хозяйстве.

11. Amacher G.S., Ollikainen M., Koskela E. Economics of forest resources. - Massachusetts: The MIT Press, 2009. $-320 \mathrm{p}$.

12. Forest Resources Assessment 2015. Terms and Definitions. URL: http://www.fao.org/docrep/017/ap862e/ap862e00.pdf (дата обращения: 13.01.2019)

13. Kovyazin V., Romanchikov A., Pasko O. Comparative analysis of forest lands cadastral appraisal estimated with regards to wood and food resources // IOP Conference Series: Earth and Environmental Science. - 2015. - V. 27. DOI: 10.1088/1755-1315/27/1/012039. URL: http://dx.doi.org/10.1088/1755-1315/27/1/012039 (дата обращения 13.01.2019).

14. Лесотаксационный справочник по Северо-Западу СССР / под ред. А.Г. Мошкалева, Г.М. Давидова, Л.Н. Яновского, В.С. Моисеева, Д.П. Столярова, Ю.И. Бурневского. - Л.: Издво Лесотехнической академии, 1984. - 320 c.

15. Brukas V., Mizaras S., Mizaraite D. Economic forest sustainability: comparison between Lithuania and Sweden // Forests. - 2015. V. 6 (1) - P. 47-64

16. New Forests. Timberland Investment Outlook, 2013-2017 // New Forests. - Chatswood: New Forests, 2013. -32 p.

17. Manley B. Discount rates used for forest valuation - results of 2009 survey // New Zealand Journal of forestry. - 2010. № 54 (4). - P. 19-23.

18. Nobre S., Erikkson L.-O., Trubins R. The use of decision support systems in forest management: analysis of FORSYS country reports // Forests. - 2016. - V. 7 (3). -72.

19. Pastorella F., Borges G., De Meo I. Usefulness and perceived usefulness of Decision Support Systems (DSSs) in participatory forest planning: the final users' point of view // IForest. - 2016. V. 9. - P. 422-429.

20. Stenger A., Harou P., Navrud S. Valuing environmental goods and services derived from the forests // Journal of Forest Economics. 2009. - № 15. - P. 1-14.

21. Gomez A. Natural resources and environmental economic valuation // Revista de Tecnologia - Journal of Technology. 2008. - V. 7. - № 2. - P. 32-40.

Поступила 16.10.2020 г.

\section{Информация об авторах}

Романчиков А.Ю., кандидат технических наук, ассистент кафедры инженерной геодезии Санкт-Петербургского горного университета.

Ковязин В.Ф., доктор биологических наук, профессор кафедры инженерной геодезии Санкт-Петербургского горного университета.

Животягина Н.И., кандидат экономических наук, старший научный сотрудник, Всероссийский научноисследовательский институт лесной генетики, селекции и биотехнологии.

Киценко А.A., аспирант кафедры инженерной геодезии Санкт-Петербургского горного университета. Данг Тхи Лан Ань, аспирант кафедры инженерной геодезии Санкт-Петербургского горного университета. 
$\operatorname{UDC} 630^{*} 6$

\title{
ALGORITHM OF FORESTLAND MASS CADASTRAL EVALUATION USING FOREST INVENTORY DATA
}

\author{
Aleksei Yu. Romanchikov1, \\ romanchicov@inbox.ru \\ Vasily F. Kovyazin ${ }^{1}$, \\ vfkedr@mail.ru \\ Nina I. Zhivotyagina², \\ pozhni@mail.ru \\ Anastasia A. Kitcenko ${ }^{1}$ \\ kna1994@bk.ru \\ Lan Anh T. Dang1, \\ lananhvtu2@gmail.com \\ 1 Saint Petersburg Mining University,

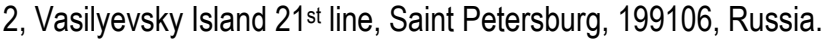 \\ 2 All-Russian Research Institute of Forest Genetics, Breeding and Biotechnology, \\ 105, Lomonosov street, Voronezh, 394087, Russia.
}

The relevance of the research is caused by the necessity of unite state cadastral evaluation method for forestlands in Russia. It is important for rational natural resources management, providing of fair fee for forestland use and for sustainable development of Russian forestry.

The aim of the research is to make an algorithm of mass forestland cadastral evaluation by forest sites. Opportunity of its usage for the whole area of Russia should be provided by taking into account regional peculiarities of forest resources harvesting.

Methods: discounting of cash flows from forest resources harvesting; regression analysis of dependence between forest inventory data and productivity of forest resources; geographic informational modelling using Maplnfo; testing of normality distribution hypothesis for obtained results; algorithm application using MS Excel.

Results and discussion. The authors have developed the algorithm of mass forestland cadastral evaluation. It makes possible to calculate cadastral value for both single forest site and whole forest district. Forest inventory data is used as basis for calculation. Algorithm can be modified by addition of discounted cash flows from forest resources harvesting which are special for particular natural zone. Method approbation is provided using forest inventory data of one of the Leningrad region forestry districts (considering regional peculiarities of forest resources harvesting). Obtained values of cadastral magnitudes (per unit) are normal law distributed. High values of cadastral value are spatially correspond to better forest sites.

\section{Key words:}

State cadastral evaluation, forestlands, forestry fund lands, forest resources, non-wood forest production.

\section{REFERENCES}

1. Pavlova V.A., Uvarova E.L. Newest technology in cadastral activities, Journal of Mining Institute, 2017, vol. 225, pp. 313-319. DOI: 10.18454/pmi.2017.3.313

2. Gosudarstvenny (natsionalny) doklad o sostoianii i ispolzovanil zemel $v$ Rossiiskoy Federatsii [State (national) review of land condition and its usage in Russian Federation]. Available at: https:// rosreestr.ru/site/activity/sostoyanie-zemel-rossii/gosudarstvennyynatsionalnyy-doklad-o-sostoyanii-i-ispolzovanii-zemel-v-rossiyskoyfederatsii/ (accessed: 8 January 2019).

3. Gosudarstvennoy kadastrovoy otsenke [On state cadastral evaluation]: Federal law 3 July 2016 no. 237-FZ (ed. 29.07.2017) Available at: http://www.consultant.ru/document/cons_doc_LAW_200504/ (accessed: 14 January 2019).

4. Ob utverzhdenii metodicheskikh ukazaniy o gosudarstvennoy kadastrovoy otsenke [On approval of state cadastral evaluation method]: Decree of Ministry of economic development 12 May 2017 no. 226. Available at: http://www.consultant.ru/document/ cons_doc_LAW_217405/ (accessed: 14 January 2019)

5. Ob utverzhdenii metodiki gosudarstvennoy kadastrovoy otsenki zemel lesnogo fonda Rossiiskoy Federatsii [On approval of state forest fund cadastral evaluation method in the Russian Federation]. Decree of Russian cadastral agency 17 October 2002, no. P/336. Available at: http://www.consultant.ru/document/cons_doc_LAW_40052/ (accessed 14 January 2019).
6. Kovyazin V., Romanchikov A., Belyaev V. Use of forest inventory data as a new method for cadastral valuation of forestlands in North-West Russia. Forestry Studies, 2014, vol. 61, pp. 69-78.

7. Romanchikov A.Y. Kadastrovaya otsenka pokrytykh drevesnoy rastitelnostiyu lesnykh zemel taezhnoy zony Severo-Zapada Rossiiskoy Federatsii pri mnogotselevom ispolzovanii ikh resursnogo potentsiala. Diss. Kand. nauk [Cadastral evaluation of wooded forestland in the taiga zone of North-West Russia for multipurpose use of its resource potential. Cand. Diss.]. Saint Petersburg, 2017. $231 \mathrm{p}$.

8. Kovyazin V.F., Martynov A.N., Melnikov E.S. Osnovy lesnogo khoziaystva i taksatsiya lesa [Basics of forestry and forest inventory]. Saint Petersburg, Lan Publ., 2012. 432 p.

9. Minaev V.N., Leontyev L.L., Kovyazin V.F. Taksatsiia lesa [Forest inventory]. Saint Petersburg, Lan Publ., 2017. 240 p.

10. Gryazkin A.V., Kondratenko N.N., Pona D.S. Nedrevesnaya produktsiya lesa [Non-wood production of forests]. Saint Petersburg, Polytechnic University Publ., 2006. 338 p.

11. Amacher G.S., Ollikainen M., Koskela E. Economics of forest resources. Massachusetts, The MIT Press, 2009. $320 \mathrm{P}$

12. Forest resources assessment 2015. Terms and definitions. Available at: http://www.fao.org/docrep/017/ap862e/ap862e00.pdf (accessed: 13 January 2018)

13. Kovyazin V., Romanchikov A., Pasko O. Comparative analysis of forest lands cadastral appraisal estimated with regards to wood and 
food resources. IOP Conference Series: Earth and Environmental Science, 2015, vol. 27. DOI: 10.1088/1755-1315/27/1/012039. Available at: http://dx.doi.org/10.1088/1755-1315/27/1/012039 (accessed 13 January 2019).

14. Moshkalev A.G., Davidov G.M., Yanovskiy L.N. Lesotaksatsionny spravochnik po Severo-Zapadu SSSR [Forest inventory reference book for the North-West of USSR]. Leningrad, Forest technical academy Publ., 1984. 320 p.

15. Brukas V., Mizaras S., Mizaraite D. Economic forest sustainability: comparison between Lithuania and Sweden. Forests, 2015, vol. 6 (1), pp. 47-64.

16. New forests - Timberland Investment Outlook, 2013-2017. New Forests. Chatswood, New Forests, 2013. 32 p.

17. Manley B. Discount rates used for forest valuation - results of 2009 survey. New Zealand Journal of forestry, 2010, no. 54 (4), pp. 19-23.
18. Nobre S., Erikkson L.-O., Trubins R. The use of decision support systems in forest management: analysis of FORSYS country reports. Forests, 2016, vol. 7 (3), 72.

19. Pastorella F., Borges G., De Meo I. Usefulness and perceived usefulness of Decision Support Systems (DSSs) in participatory forest planning: the final users' point of view. IForest, 2016, vol. 9. pp. 422-429.

20. Stenger A., Harou P., Navrud S. Valuing environmental goods and services derived from the forests. Journal of Forest Economics, 2009, no. 15, pp. 1-14.

21. Gomez A. Natural resources and environmental economic valuation. Revista de Tecnologia - Journal of Technology, 2008, vol. 7, no. 2 , pp. $32-40$

Received: 16 October 2020.

Information about the authors

Aleksei Yu. Romanchikov, Cand. Sc., assistant professor, Saint Petersburg Mining University.

Vasily F. Kovyazin, Dr. Sc., professor, Saint Petersburg Mining University.

Nina I. Zhivotyagina, Cand. Sc., senior fellow, All-Russian Research Institute of Forest Genetics, Breeding and Biotechnology.

Anastasia A. Kitcenko, postgraduate student, Saint Petersburg Mining University.

Lan Anh T. Dang, postgraduate student, Saint Petersburg Mining University. 